\title{
Variations in the negative recency effect
}

\author{
JOHN T. E. RICHARDSON \\ Brunel University, Uxbridge, Middlesex UB8 3PH, England
}

\begin{abstract}
The negative recency effect has been reliably demonstrated in a final, cumulative recall test but not in an initial recall test delayed by an irrelevant interpolated activity. One explanation of this is that a distractor task induces elaborative encoding on the terminal list items; however, a negative recency effect has been found in an initial, delayed recall test following auditory presentation. Another explanation of variations in negative recency is that visual presentation induces elaborative encoding on the terminal list items. An experiment was carried out to test this hypothesis, using immediate initial testing and visual presentation. A negative recency effect was found with material of high imageability but not with material of low imageability. It was concluded that the negative recency effect is caused by the fact that subjects do not image the last few items presented in a free recall task, but that, under conditions of visual presentation, an irrelevant distractor task will induce the employment of mental imagery as an elaborative code on all of the items in a list.
\end{abstract}

When a series of lists is presented for immediate free recall and the subjects are given an unanticipated final recall test in which they are required to produce as many items from all of the lists as they can remember, items presented in the last few serial positions are less well recalled than earlier items (Craik, 1970). This "negative recency effect" was originally attributed to terminal items' receiving less rehearsal and therefore poorer registration in secondary memory than earlier items. However, Craik and Watkins (1973) found that the recall of the terminal items in a final recall test was not improved by their being repeated continuously for $20 \mathrm{sec}$ between presentation and the initial recall test. This suggested that it was the quality of rehearsal and not the quantity of rehearsal that influenced recall performance. It was concluded that the negative recency effect was caused by rehearsal's being employed as a "maintaining" activity rather than as an "elaborative" activity.

An important problem for this research is that many studies have failed to find a negative recency effect in an initial recall test delayed by an irrelevant interpolated activity (e.g., Bruce \& Crowley, 1970; Glanzer \& Cunitz, 1966; Glanzer, Gianutsos, \& Dubin, 1969; Jacoby \& Bartz, 1972; Postman \& Phillips, 1965; Raymond, 1969; Richardson \& Baddeley, 1975). Watkins and Watkins (1974) suggested that an irrelevant distractor task induced an elaborative mode of rehearsal for the last few list items. They argued that such rehearsal would also be employed when list length was varied from trial to trial in an unpredictable manner, so that it would not be possible for subjects to identify the terminal items while they were being presented. Under such circumstances, subjects demonstrated a reduced

Requests for reprints should be sent to Dr. J. T. E. Richardson, Department of Psychology, Brunel University, Uxbridge, Middlesex UB8 3PH, England. recency effect in the initial recall test and no negative recency effect in the final recall test.

A somewhat different account of variations in negative recency was offered by Gardiner, Thompson, and Maskarinec (1974). They noted that most of the studies that had failed to find a negative recency effect in an initial, delayed recall test had used visual presentation. They found a negative recency effect in such a test, but only under auditory presentation, which suggests that visual presentation promotes the use of rehearsal even on the last few items in a list. Such an account would predict that no recency effect would be found in a final recall test following visual presentation and immediate initial recall. Paivio (1975) reported unpublished findings by Bleasdale and Katz that are in accord with this prediction, but Dalezman (1975) obtained a negative recency effect with visual presentation under certain conditions.

Nevertheless, the evidence reviewed up to this point has to be qualified in the light of research relating the negative recency effect to the concept of mental imagery. Richardson (1974) found a negative recency effect with concrete, imageable material but not with abstract material of low imageability. It was suggested that subjects normally employ mental imagery in their learning of early or middle items but not in their learning of the last few items presented. By this account, the negative recency effect is caused by the fact that mental imagery cannot therefore be used to retrieve the last few items in each list. It can be used to retrieve items presented earlier in the list, provided that they are imageable, and so, a negative recency effect will be observed in a final recall test if at least some of the items presented in the early or middle serial positions are of high imageability. More recent experiments (Richardson, 1978b) have demonstrated that inducing the employment of mental imagery on all of the items in a list (including the last few items presented) by suitable 
mnemonic instructions will remove the negative recency effect. In terms of the framework suggested by Craik and Watkins (1973), these findings indicate that the negative recency effect is not caused by rehearsal's being employed as a maintaining activity rather than as an elaborative activity on the terminal list items. Rather, the negative recency effect appears to be caused by the subjects' failure to employ one particular kind of elaborative encoding (i.e., mental imagery) on the last few items of a list (Richardson, 1974).

One may now reconsider and reinterpret the alternative explanations of variation in negative recency in an initial recall test delayed by an irrelevant interpolated task. The account offered by Watkins and Watkins (1974) leads to the proposal that an irrelevant distractor task will induce the employment of mental imagery as an elaborative code even on the last few items in a list. On the other hand, the account offered by Gardiner et al. (1974) leads to the proposal that visual presentation will remove the negative recency effect by promoting the use of mental imagery in this manner. The first proposal was contradicted by the results of Richardson (1978b), who obtained a negative recency effect in an initial recall test delayed by an irrelevant interpolated activity, provided that the material was of high imageability. This was taken as support for the second proposal. In a further experiment, Richardson (1978b) failed to find a negative recency effect in a final recall test for lists of concrete nouns, following visual presentation and an immediate initial recall test. However, this negative finding was based upon the recall of only four lists, each of nine nouns. It is more appropriate to evaluate the two proposals by repeating Richardson's (1974) original experiment under conditions of visual presentation. If elaborative encoding is affected by the modality of presentation, there should be no negative recency effect. On the other hand, if elaborative encoding is affected by an irrelevant distractor task, but not by the modality of presentation, there should be a negative recency effect similar to that found under auditory presentation.

\section{METHOD}

\section{Subjects}

Five male and five female undergraduate students at Brunel University were paid for their participation in this experiment.

\section{Materials \\ Ten lists of 10 English nouns were selected from the norms of Paivio, Yuille, and Madigan (1968). Half of the lists contained words with imagery and concreteness ratings of 6.0 or more; the other half contained words with imagery and concreteness ratings of less than 6.0. The mean imagery ratings of the two sets of words were 6.50 and 4.38 , and the mean concreteness ratings were 6.78 and 3.88. All of the words had ratings of AA or A in the norms of Thorndike and Lorge (1944).}

Procedure

The subjects were tested individually, and the 10 lists were presented in the same randomized order to each subject for immediate free recall. (The original study using auditory presentation compared two different randomized orders and found no sign of an effect upon the pattern of results.) The words were presented on white record cards, printed in lower case type, at a rate of one every $3 \mathrm{sec}$, and $30 \mathrm{sec}$ was allowed for the oral recall of each list. Following the initial recall of List 10, the subjects were given an unanticipated final recall test on all of the words presented. They were allowed $3 \mathrm{~min}$ for the final oral recall.

\section{RESULTS}

Table 1 shows the mean percentage correct at each serial position for the concrete and abstract material in the initial and final tests. An analysis of variance was carried out on each subject's performance in each test on each item. This employed two random factors, subjects and items, and one fixed factor, tests; the second random factor was nested under the fixed factors of imagery and serial position. There were significant effects of imagery [quasi $F(1,44)=4.30, p<.05$ ], serial position $[F(9,80)=2.12, p<.05]$, and tests $[F(1,9)=205.8, p<.001]$. In addition, the interaction between serial position and test was significant $[F(9,81)=$ $11.0, \mathrm{p}<.001]$. The interaction between imagery and serial position was not significant $[F(9,80)=1.31$, $p>.05]$, nor was that between imagery and tests $(\mathrm{F}<1)$, nor that between imagery, serial position, and tests $[F(9,81)=1.52, p<.1]$. However, inspection of Table 1 shows that the effect of imagery was confined to the first six or seven serial positions in both the immediate and final tests.

To investigate the possibility of a negative recency effect, a posteriori tests compared the performance at Serial Positions 3-6 with that at Serial Positions 7-10 in the final recall test. This contrast was significant for the concrete items $[F(1,160)=7.98, p<.01]$ but not for the abstract items $(F<1)$. Table 1 shows that there was a reliable negative recency effect on the concrete items but not on the abstract items. Finally, further a posteriori tests showed that the effect of imagery was significant over Serial Positions 3-6 in the final test $[F(1,160)=6.98, p<.01]$ but not over Serial Positions 7-10 in the final test $(F<1)$.

Table 1

Mean Percentage Correct on Concrete and Abstract Material in Initial and Final Recall

\begin{tabular}{ccccc}
\hline \multirow{2}{*}{$\begin{array}{c}\text { Serial } \\
\text { Position }\end{array}$} & \multicolumn{2}{c}{ Initial Recall } & & \multicolumn{2}{c}{ Final Recall } \\
\cline { 2 - 3 } & Concrete & Abstract & Concrete & Abstract \\
\hline 1 & 76 & 62 & 52 & 24 \\
2 & 66 & 48 & 38 & 32 \\
3 & 58 & 44 & 44 & 18 \\
4 & 54 & 24 & 32 & 14 \\
5 & 52 & 46 & 26 & 18 \\
6 & 62 & 54 & 34 & 28 \\
7 & 58 & 48 & 16 & 24 \\
8 & 60 & 66 & 18 & 32 \\
9 & 74 & 84 & 28 & 20 \\
10 & 80 & 86 & 12 & 8 \\
\hline
\end{tabular}




\section{DISCUSSION}

Inspection of the results shown in Table 1 indicates that the outcome of the present investigation was essentially identical to that of Richardson's (1974) original study. There was no negative recency effect in the case of the abstract material, although there was a substantial effect in the case of the concrete material. These results support the explanation of the negative recency effect offered by Richardson (1974). On the one hand, it is reasonable to explain the positive effect of imageability upon the recall of items presented in the early and middle serial positions in terms of the psychological process of mental imagery. On the other hand, it is reasonable to explain the failure to find such an effect upon the recall of the terminal list items in terms of the subjects' failure to employ mental imagery as a mnemonic code. For the pattern of results shown in Table 1, this implies that the negative recency effect is to be explained in terms of the subjects' failure to employ imagery as a form of elaborative encoding on the last few items of a list.

However, the present investigation was carried out to test two specific hypotheses concerning variations in the negative recency effect. The suggestion had been put forward by Richardson $(1978 \mathrm{a}, 1978 \mathrm{~b})$ that visual presentation would promote the use of mental imagery as an elaborative code even on the terminal list items. This entailed that a negative recency effect would not be found under conditions of visual presentation, even with material of high imageability. The present results, obtained with visual presentation, were essentially the same as those of Richardson (1974), obtained with auditory presentation: A substantial negative recency effect occurred with material of high imageability. Thus, Richardson's suggestion concerning the effect of presentation modality upon the negative recency effect must be rejected.

An alternative account of variations in the negative recency effect was derived from the suggestions of Watkins and Watkins (1974). This proposed that the employment of mental imagery would be promoted by the interpolation of an irrelevant distractor task between the presentation and the initial recall of a list, but not by the use of visual presentation. This entailed that a negative recency effect would be obtained with material of high imageability under conditions of visual presentation, which was confirmed by the present findings. However, this account is contradicted by the results of Richardson (1978b), who found a negative recency effect with material of high imageability in an initial recall test delayed by an irrelevant distractor task and in the subsequent final recall test.

Neither suggestion concerning the manipulations that remove the negative recency effect appears to be adequate. Rather, it seems to be both necessary and appropriate to explain the observed variations in the negative recency effect by combining the two proposals described above. The effect itself is to be attributed to the subjects' failure to employ mental imagery as a specific form of elaborative encoding in the case of terminal list items. However, under conditions of visual presentation, the interpolation of an irrelevant distractor task between the presentation and the recall of a list will induce the employment of mental imagery as an elaborative code on all of the items in a list, including those in the terminal serial positions; this will remove the negative recency effect, both in the delayed initial recall test and in a subsequent final recall test.

The negative recency effect appears to be a relatively labile phenomenon, in that it is now known to be susceptible to variations in the retrieval strategies employed by subjects at the time of the initial recall test (Dalezman, 1975). Nevertheless, this does not entail that variations in negative recency that result from other kinds of experimental manipulation are to be explained merely in terms of correlated changes in output order. Indeed, the results obtained by Richardson $(1974,1978 \mathrm{~b})$ and the findings of the present study indicate that, with constant retrieval instructions, the negative recency effect is susceptible to variations in stimulus properties and in learning strategies, and that these variations produce changes in the subjects' employment of mental imagery as a form of elaborative encoding in long-term memory.

\section{REFERENCES}

Bruce, D., \& Crowley, J. J. Acoustic similarity effects on retrieval from secondary memory. Journal of Verbal Learning and Verbal Behavior, 1970, 9, 190-196.

CraIK, F. I. M. The fate of primary memory items in free recall. Journal of Verbal Learning and Verbal Behavior, 1970, 9, 143-148.

Craik, F. I. M., \& Watkins, M. J. The role of rehearsal in short-term memory. Journal of Verbal Learning and Verbal Behavior, 1973, 12, 599-607.

Dalezman, J. J. Effects of output order on immediate, delayed, and final recall performance. Journal of Experimental Psychology: Human Learning and Memory, 1975, 2, 597-608.

Gardiner, J. M., Thompson, C. P., \& Maskarinec, A. S. Negative recency in initial free recall. Journal of Experimental Psychology, 1974, 103, 71-78.

Glanzer, M., \& Cunitz, A. R. Two storage mechanisms in free recall. Journal of Verbal Learning and Verbal Behavior, 1966, 5, 351-360.

Glanzer, M., Gianutsos, R., \& Dubin, S. The removal of items from short-term storage. Journal of Verbal Learning and Verbal Behavior, 1969, 8, 435-447.

JACOBY, L. L., \& BARTZ, W. H. Rehearsal and transfer to LTM. Journal of Verbal Learning and Verbal Behavior, 1972, 11, 561-565.

Paivio, A. Imagery and long-term memory. In A. Kennedy \& A. Wilkes (Eds.), Studies in long term memory. London: Wiley, 1975.

Paivio, A., Yuille, J. C., \& Madigan, S. Concreteness, imagery, and meaningfulness values for 925 nouns. Journal of Experimental Psychology Monograph, 1968, 76(1, Pt. 2).

Postman, L., \& Phillips, L. W. Short-term temporal changes in free recall. Quarterly Journal of Experimental Psychology, $1965,17,132-138$.

RAYmond, B. Short-term storage and long-term storage in free recall. Journal of Verbal Learning and Verbal Behavior, 1969, 8, 567-574.

RichaRDSON, J. T. E. Imagery and free recall. Journal of Verbal Learning and Verbal Behavior, 1974, 13, 709-713.

Richardson, J. T. E. Memory for pictures and words, and the negative recency effect. Perceptual and Motor Skills, 1978, 47, 967-970. (a)

Richardson, J. T. E. Mental imagery and the distinction between primary and secondary memory. Quarterly Journal of Experimental Psychology, 1978, 30, 471-485. (b)

Richardson, J. T. E., \& Baddeley, A. D. The effect of articulatory suppression in free recall. Journal of Verbal Learning and Verbal Behavior, 1975, 14, 623-629.

Thorndike, E. L., \& LoRge, I. The teacher's word book of 30,000 words. New York: Teachers College, 1944.

Watkins, M. J., \& Watkins, O. C. Processing of recency items for free recall. Journal of Experimental Psychology, 1974, $102,488-493$.

(Received for publication August 28, 1979.) 